\title{
3 \\ Improved Parameter Estimation Techniques for Soil Storage Capacity
}

\author{
Michael A. Gregory and Brett A. Cunningham
}

The capacity of surface soil layers to store infiltrated water is a critical factor when simulating runoff response in some natural or developing watersheds. Often, the underlying assumption that is made in hydrologic analyses is that the unsaturated zone is deep enough for unsaturated infiltration to occur throughout the event. However, in some areas this assumption is not valid, particularly for larger storm events. When the soil storage capacity in the unsaturated zone is exceeded, infiltration capacity is reduced or eliminated since capacity can only be regenerated by groundwater flow out of the surficial aquifer or by evapotranspiration (ET). These rates of groundwater flow or ET are often substantially smaller than infiltration rates. Current methods for estimating soil storage capacities are typically based on curve numbers, which use general soil and land use characteristics and most often do not make use of important published soil survey data. This chapter presents a physically based method for estimating the soil storage capacity for specific soil types using data that are readily available in GIS format.

\subsection{Introduction}

Soil storage capacity is defined in this chapter as the volume of soil pores in the unsaturated zone that is available to store infiltrated surface runoff. This capacity depends on a number of factors, including the physical and chemical

Gregory, M. and B. Cunningham. 2004. "Improved Parameter Estimation Techniques for Soil Storage Capacity." Journal of Water Management Modeling R220-03. doi:

10.14796/JWMM.R220-03.

(C) CHI 2004 www.chijournal.org ISSN: 2292-6062 (Formerly in Innovative Modeling of

Urban Water Systems. ISBN: 0-9683681-9-0) 
properties of the soil, water content of the soil, and the depth to the water table or some other confining layer. Soil properties vary vertically within the surface profile, spatially even within relatively small areas, and temporally as the soil water content changes during and after rainfall events.

The soil storage capacity is an important consideration in areas where the unsaturated zone is only a few feet deep or less, particularly for large volume storm events. Under these conditions, the soil storage capacity (expressed as a depth over a unit area) of a particular soil can typically vary between 0 and 10 in $(254 \mathrm{~mm})$ or more. As the soil storage capacity approaches zero (e.g. during heavy rainfall and/or high groundwater conditions), infiltration can be significantly reduced or no longer take place and essentially all subsequent rainfall becomes runoff since evapotranspiration and percolation rates are generally very low compared to unsaturated infiltration rates and rainfall intensities. At higher soil storage capacities (e.g., during long dry periods and/ or low groundwater conditions), all of the rainfall can potentially infiltrate, resulting in zero runoff. Therefore, the soil storage capacity can mean the difference between essentially all or no runoff for a given soil type and rainfall event.

Popular infiltration calculation methods such as the Green-Ampt, Holtan, and Horton equations were developed with no explicit dependency on the water table, i.e. these equations assume a sufficiently deep unsaturated zone. As a result, the parameters for these equations are sometimes modified beyond realistic values during calibration in an attempt to account for a reduced soil storage capacity.

The curve number method implicitly incorporates soil storage capacity, but the capacity is most often based on general soil and land use characteristics rather than the actual capacity in the unsaturated zone. Additionally, a variety of computer models have extended infiltration equations such as the GreenAmpt and Horton equations to account for soil storage capacity (Johanson et al., 1984; Huber and Dickinson, 1988). Even with these models, current techniques for estimating the soil storage capacity are often only based on very simple, empirical methods that do not make use of published soil survey data from the U.S. Department of Agriculture's Natural Resources Conservation Service (NRCS, formerly the Soil Conservation Service, SCS).

The purpose of this chapter is to present a physically based method for estimating the soil storage capacity of specific soil map units. These methods are based on available NRCS soil survey data, which includes characteristic soil and water properties, and water table depth information. 


\subsection{Background}

This section includes a summary of the basic soil and water relationships and the theory for estimating soil storage capacity. In addition, published soil survey data sources are described.

\subsubsection{Soil - Water Relationships}

Soil is a complex, multi-phase, heterogeneous system of various gases, liquids and solids. For evaluation purposes in this chapter, these phases are ideally assumed to be air, water, and soil particles, respectively.

Figure 3.1 illustrates the volume and mass components of air, water and solid particles within a soil sample. The volume of the void space is the total volume of air and water, and the mass within this void space is simply the mass of water, since the mass of air is negligible.
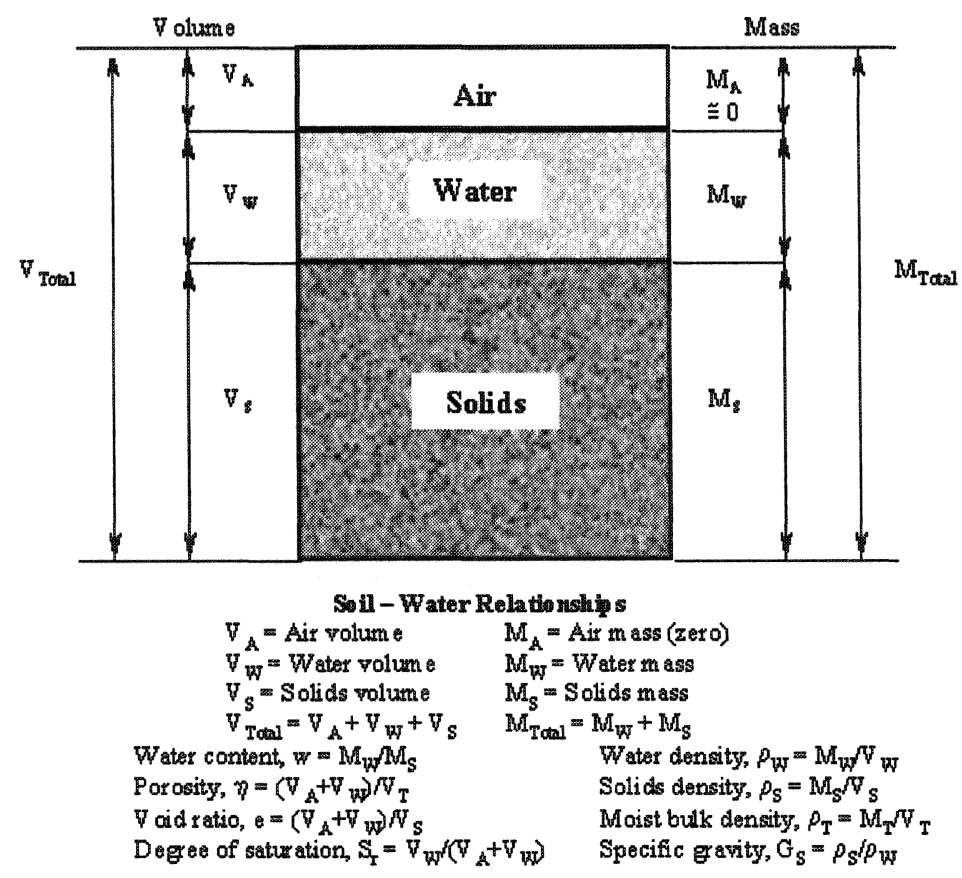

Figure 3.1 Soil phase diagram and definitions. 
Of all the relationships defined on Figure 3.1, the notable ones for this chapter are the following:

- Water content, $\mathrm{w}$, relates the ratio of the mass of water to the mass of soil solids. If the weight of the water exceeds the weight of the dry soil (e.g. in mucky soils), then w will exceed $100 \%$.

- Porosity, $\eta$, relates the ratio of the volume of voids to the total sample volume.

- Degree of saturation, $\mathrm{S}_{\mathrm{r}}$, is the ratio of the volume of water to the volume of voids.

- Moist bulk density, $\rho_{\mathrm{T}}$, is the ratio of soil mass to soil volume.

Figure 3.2 shows a conceptual moisture profile for two soil types (adapted from Figure X-6, page 551, Huber and Dickinson, 1988). The horizontal axis represents the water content and the vertical axis represents the soil sample condition, expressed by the degree of saturation and by the energy potential of the soil.

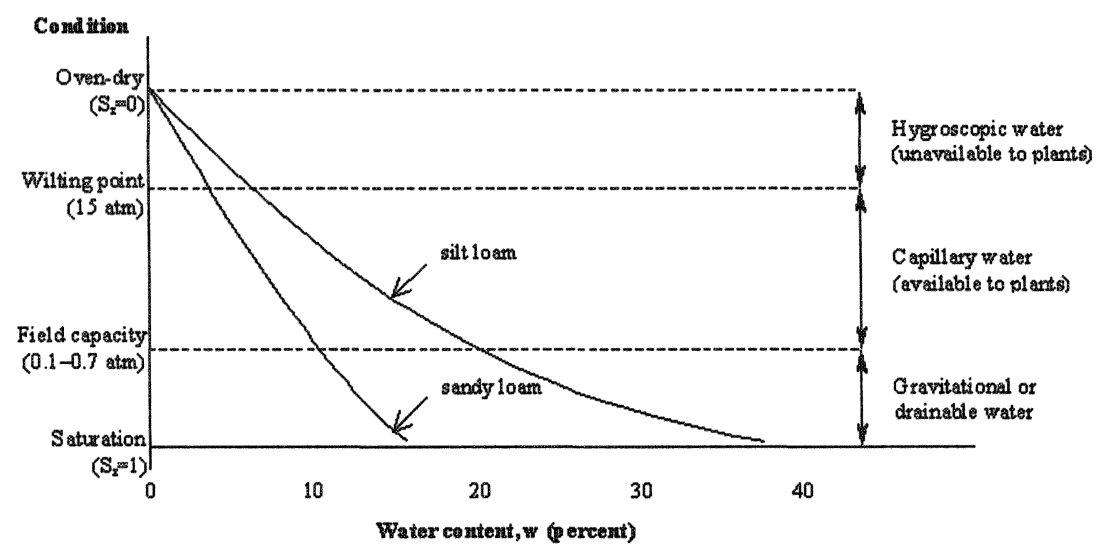

Figure 3.2 Water content relationships in soil void space.

The degree of saturation ranges from oven-dry $(\mathrm{Sr}=0$, i.e., no water in the void space) to complete saturation $\left(\mathrm{S}_{\mathrm{T}}=1\right.$, i.e. no air in the void space). Two points are commonly used to denote intermediate values of the degree of saturation: the wilting point and the field capacity. These values are based on the energy potential of water, expressed by the tension of water held in the soil. The water content at the wilting point is often determined at a tension of approximately $15 \mathrm{~atm}$ and represents the point at which plant roots can no longer draw water from the void space. The water content at the field capacity is often determined at a tension between 0.1-0.7 atm, depending on the soil type. 
Field capacity represents the maximum amount of water that a soil can hold against gravity, that is, the point at which gravity movement stops and all drainable water has percolated.

The water content range between oven-dry and the wilting point defines hygroscopic water, which represents water that is unavailable to plants since the roots cannot overcome the high tension. The water content between the wilting point and field capacity defines capillary water, which represents water that is readily available to plants. Finally, the water content between field capacity and complete saturation defines gravitational water, which represents water that is quickly drained by gravity under most conditions and is effectively unavailable to plants.

The focus of this chapter is the drainable water content range. In this context, soil storage capacity quantifies the ability of a specific soil to hold gravitational water and can be determined by taking the difference between the water content at field capacity and at complete saturation. When this difference is expressed in terms of the volume (i.e. porosity), it is commonly referred to as the drainable porosity. The soil storage capacity is then simply the product of the drainable porosity times the depth of the unsaturated zone.

From the definitions in Figure 3.1, two equations can be derived that form the basis for the parameter estimation techniques described in this chapter. At complete saturation $\left(\mathrm{S}_{\mathrm{r}}=1\right)$,

$$
w=\frac{\rho_{s}-\rho_{T}}{G_{s}\left(\rho_{r}-\rho_{w}\right)}
$$

and for all values of $\mathrm{S}_{\mathrm{r}}$,

$$
\eta=1-\frac{\rho_{r}}{\rho_{s}(w+1)}
$$

where:

$$
\begin{aligned}
w & =\text { water content (percent by weight) } \\
\eta & =\text { porosity (percent by volume) } \\
\rho_{S} & =\text { soil particle (solids) density }\left(\mathrm{g} / \mathrm{cm}^{3}\right) \\
\rho_{T} & =\text { moist bulk density }\left(\mathrm{g} / \mathrm{cm}^{3}\right) \\
\rho_{W} & =\text { water density }\left(\mathrm{g} / \mathrm{cm}^{3}\right), \text { and } \\
G_{S} & =\text { specific gravity of the soil particle (dimensionless). }
\end{aligned}
$$

\subsubsection{Physical Processes in Surface Soil Layers}

Infiltration and percolation within surface soil layers are among the physical processes that are most important in hydrologic analyses. Infiltration involves 
the downward movement of rainfall into the unsaturated zone and is of primary interest in the study of surface water hydrology. Percolation involves the movement of water from the unsaturated zone into the saturated zone and is of primary interest in the study of groundwater hydrology. The water table represents the boundary between the unsaturated and saturated zones.

The rainfall rate, infiltration capacity, and water table depth determine how much water infiltrates into the unsaturated zone and the percolation capacity of the saturated zone may determine how much water stays there. The amount of water in the unsaturated zone affects the rate of flow either way.

Due to the difference in time scales of infiltration and percolation rates, among other things, the study of surface and ground water hydrology are often separate and distinct analyses. The common ground between these disciplines is the unsaturated zone. Often, the study of surface water hydrology treats this zone as an infinite sink, where infiltration is assumed to be free of the rate and volume limitations imposed by a dynamic, rising water table. Likewise, the study of groundwater hydrology often treats the unsaturated zone as an infinite source, where percolation is assumed to be free of the rate and volume limitations imposed by the dynamic response of water in the unsaturated zone due to rainfall. As a result, the interdependencies of the hydraulics in both unsaturated and saturated zones are often ignored.

During heavy rainfall, available soil pores in the unsaturated zone can completely fill up, effectively raising the water table to the surface. When infiltrated rainfall exceeds the available soil storage capacity, infiltration may cease and further rainfall may all become runoff. At a minimum, sub-surface flow is no longer governed by infiltration equations: rather, it becomes part of the groundwater flow regime, where percolation rates are often at least an order of magnitude less than infiltration rates. The presence of a high water table will therefore invalidate the often-used assumption of an infinite sink, since the depth of the unsaturated zone is greatly restricted.

\subsubsection{Horton Infiltration Equation}

According to the Horton infiltration equation, when the rainfall intensity exceeds the infiltration capacity, the rate of infiltration decreases exponentially with time until it reaches a final constant rate. The rate of infiltration is described by the following equation (Horton, 1939):

$$
f(t)=f_{c}+\left(f_{o}-f_{c}\right) e^{-k t}
$$


where:

$$
\begin{aligned}
f(t)= & \text { infiltration capacity at time } \mathrm{t} \text { (measured in units of } \\
& \text { inches per hour, in } / \mathrm{h}), \\
f_{c}= & \text { minimum (or final) infiltration capacity }(\mathrm{in} / \mathrm{h}), \\
f_{o}= & \text { maximum (or initial) infiltration capacity }(\mathrm{in} / \mathrm{h}), \\
k= & \text { exponential decay constant }(\mathrm{h}-1), \text { and } \\
t= & \text { time }(\mathrm{h}) .
\end{aligned}
$$

The infiltration volume can be determined by integrating the infiltration rate with respect to time, that is:

where:

$$
F(t)=f_{c} t+\left(f_{o}-f_{c}\right)\left(1-e^{-k t}\right) / k
$$

$$
\begin{gathered}
F(t)=\text { infiltration capacity of the soil at time } t \text { (measured in } \\
\text { units of inches, in), and } \\
\text { all other terms are defined above in Equation 3.3. }
\end{gathered}
$$

Typical parameter values for $f_{o}, f_{c}$, and $k$ can be found in hydrology textbooks and computer model user's manuals (e.g. Haan et al., 1982; Chow et al., 1988; Huber and Dickinson, 1988; Bedient and Huber, 1992; and Pitt and Lantrip, 2000). In practice, the final infiltration capacity, $f_{c}$, is often taken as the saturated hydraulic conductivity of the soil (Bedient and Huber, 1992). The initial infiltration capacity, $\mathrm{f}_{\mathrm{o}}$, (and $\mathrm{k}$ to some extent) is dependent on the initial water content of the soil (Haan et al., 1982). The decay constant, $\mathrm{k}$, is an empirical parameter that controls the rate of decrease in infiltration capacity during a rainfall event. A lower decay constant gives a slower rate of decrease in infiltration capacity; a higher decay constant forces the infiltration capacity to reach its minimum value more quickly.

Figure 3.3 shows the Horton equation for a soil with the following characteristics: $\mathrm{f}_{\mathrm{o}}=10$ in $(254 \mathrm{~mm}) / \mathrm{h}, \mathrm{f}_{\mathrm{c}}=2$ in $(508 \mathrm{~mm}) / \mathrm{h}$, and $\mathrm{k}=1 \mathrm{~h}^{-1}$. The infiltration rate is shown on the left vertical axis, and it decreases exponentially from the initial value of $10 \mathrm{in} / \mathrm{h}$ to the final value of $2 \mathrm{in} / \mathrm{h}$ after a period of approximately $6 \mathrm{~h}$. The infiltration volume is shown on the right vertical axis, and it increases exponentially from the beginning of rainfall until a steady-state infiltration rate is achieved (i.e. hour 6), after which time it increases linearly for as long as the rainfall continues.

The Horton equation describes the potential infiltration rate. As long as the rainfall rate exceeds the infiltration capacity, the rate of infiltration will follow the curve shown in Figure 3.3. In cases where the rainfall intensity is less than 


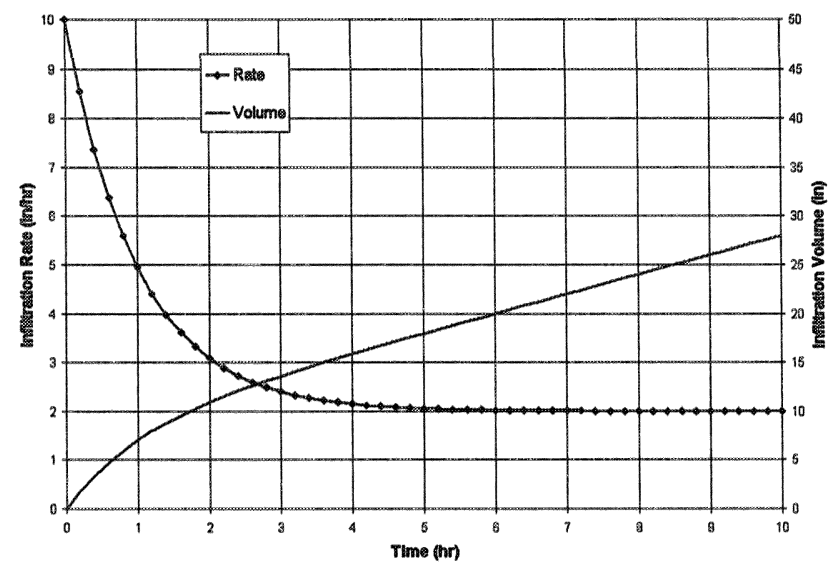

Figure 3.3 Horton infiltration rate and volume.

the infiltration capacity (that is when the rainfall rate is limiting) the rate of infiltration will generally be equal to the rainfall rate.

For surface water analyses, the Horton equation must be modified to account for variable rainfall conditions and for cases when the soil storage capacity is exceeded. During periods of dry weather, the infiltration capacity of a soil is regenerated, and is often assumed to increase exponentially back to the initial infiltration rate (Huber and Dickinson, 1988).

During conditions of very heavy rainfall and/or high groundwater conditions, the soil storage capacity can approach zero, at which point infiltration is nolonger Hortonian and can even become zero. The Horton infiltration equation assumes conveyance through an unsaturated soil zone and must be modified in order to represent these saturated soil conditions.

Figure 3.4 shows the impact of exceeding the soil storage capacity on infiltration rate and volume. If the soil represented in Figure 3.3 had a soil storage capacity of 14 in $(356 \mathrm{~mm})$, the infiltration rate would drop to zero after approximately 3.2 hours. The resulting infiltration rate and volume curves shown are very different than those in Figure 3.3. Computer models and methods that do not account for the soil storage capacity would overestimate infiltration and therefore underestimate the surface runoff component.

\subsubsection{Available Data Resources}

Published soil survey reports from NRCS are available for counties throughout the U.S. A number of these are available on-line at http://soils.usda.gov/survey/ online_surveys/, and most have been converted into GIS format. 


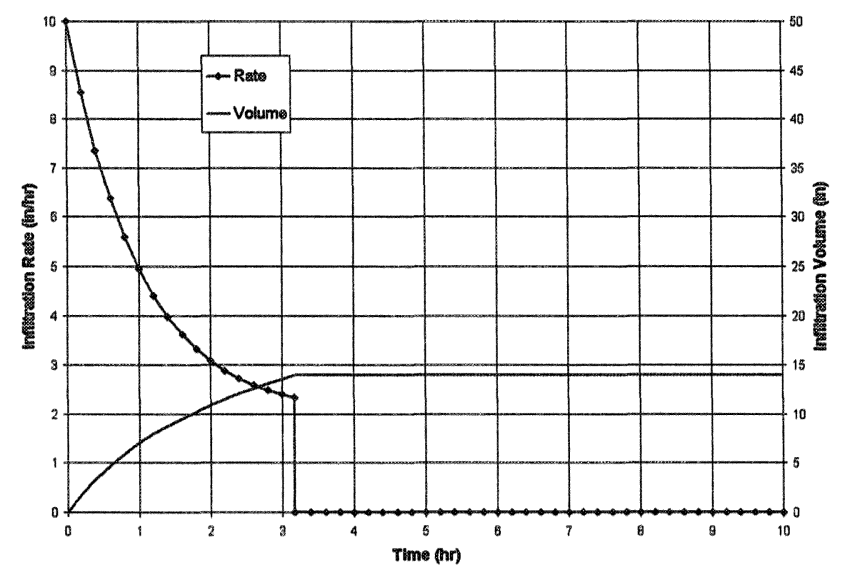

Figure 3.4 Horton infiltration rate and volume (with soil storage capacity $=14$ in).

Soil types are categorized by a unique soil map symbol and soil name, collectively referred to in this chapter as the soil map unit. Each soil survey includes data related to soil and water properties for county soil map units. Certain soil types were not assigned hydrologic properties due to either unknown or extremely variable properties. These types include highly disturbed soils as dumps, quarry/pits, and urban lands where soil properties must be estimated from other sources.

Soil survey data needed to apply the parameter estimation techniques developed in this chapter are commonly grouped into the following tables, as described in subsequent sections below.

\section{Physical Analyses of Selected Soils}

Figure 3.5 shows a sample of the Physical Analyses of Selected Soils table for Calhoun County, Florida. Not all county soil surveys include this detailed survey data, due to a lack of field measurements. Even soil surveys that do include this detailed data do not include data for all soil map units within the county.

The table includes detailed physical, chemical and mineralogical properties based on laboratory analyses of selected soils at various depths below the ground. Soils in each map unit are generally subdivided into 4 to 8 layers, down to a typical depth of $80 \mathrm{in}$. For each layer, the particle size distribution, moist bulk density, and water content at $10 \mathrm{kPa}, 33 \mathrm{kPa}$, and $1500 \mathrm{kPa}$ (approximately $1 / 10 \mathrm{~atm}, 1 / 3 \mathrm{~atm}$, and $15 \mathrm{~atm}$, respectively) are tabulated. 


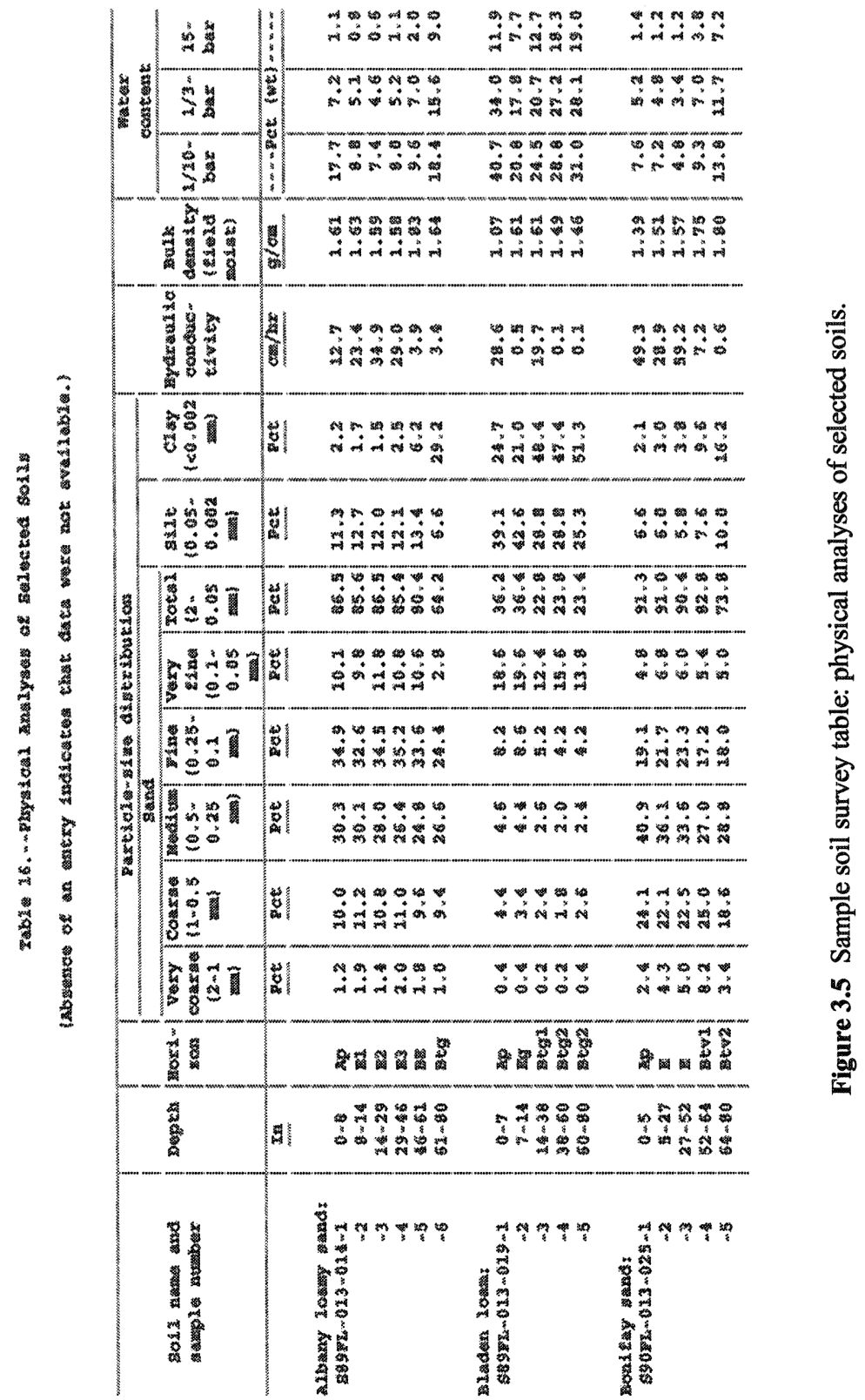




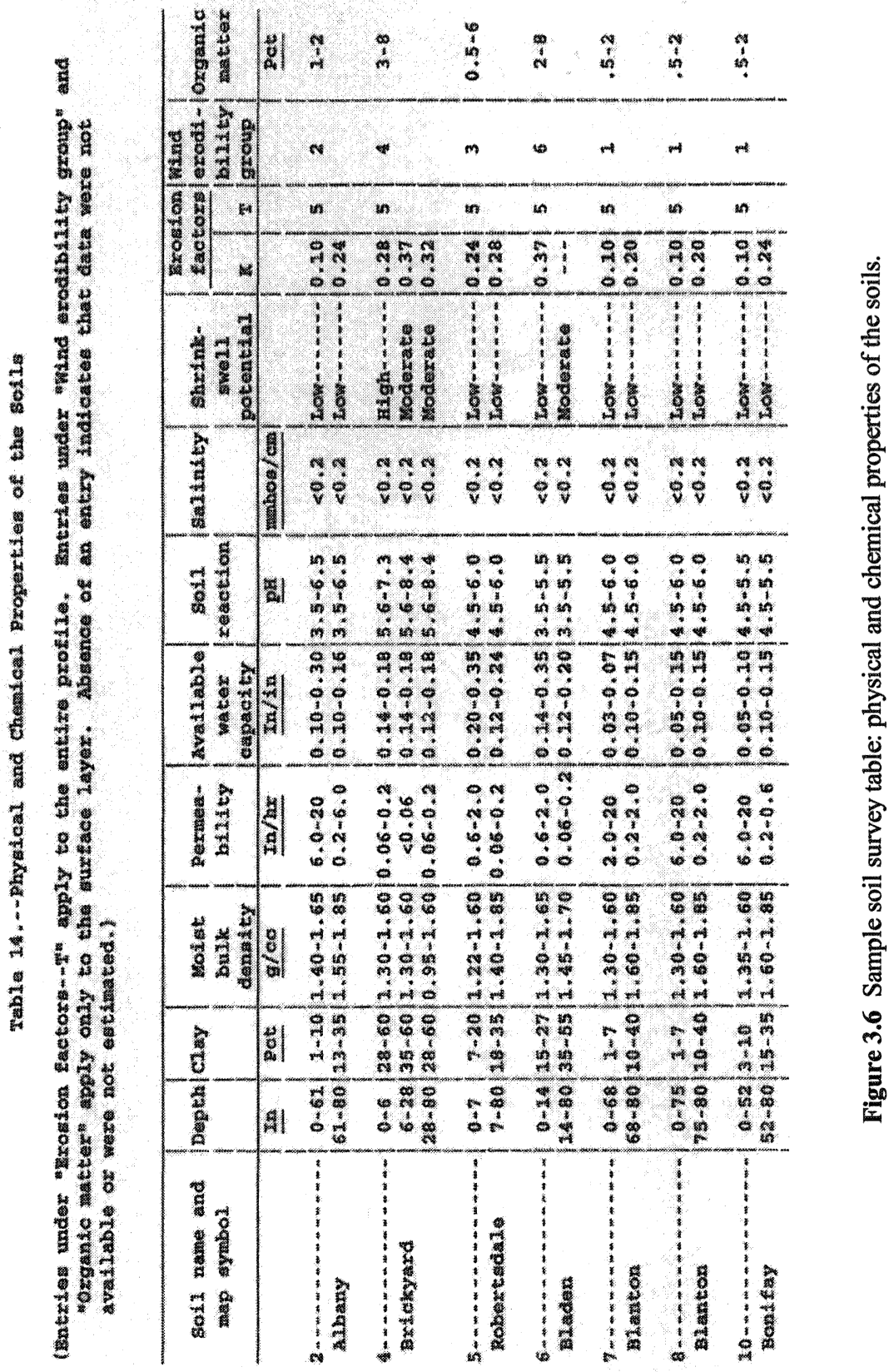


Physical and Chemical Properties of the Soils

Figure 3.6 shows a sample of the Physical and Chemical Properties of the Soils table for Calhoun County, Florida. This is a standard NRCS soil survey table and includes data for all soil map units within the county.

The table includes a variety of physical, chemical and mineralogical properties based on laboratory analyses of selected soils at various depths below the ground. For the purposes of this study, the most important data in this table includes estimates of the moist bulk density, based on field observations and on laboratory test data for these and similar soil types. It is worth noting that the column titled Available Water Capacity refers to capillary water (i.e. available to plants) and does not apply to drainable water, the topic of this chapter. Soils in each map unit are generally subdivided into 1 to 5 layers, down to a typical depth of 80 in. For each layer, moist bulk density estimates are expressed as a range of values (e.g. $1.45-1.60 \mathrm{~g} / \mathrm{cm}^{3}$ ).

\section{Soil and Water Features}

Figure 3.7 shows a sample of the Soil and Water Features table for Calhoun County, Florida. This is a standard NRCS soil survey table and includes data for all soil map units within the county.

The table includes a variety of physical information including the seasonal high water table (HWT) depth and the hydrologic soil group (HSG) for each map unit. The HWT depth was measured in feet below the surface and represents the highest sustained elevation of the saturated zone. Often, a range of depths is given along with an estimate of the duration in months.

There are four HSG categories: Group A, B, C, and D. Group A soils have a high infiltration potential and low runoff potential, and Group D soils have a low infiltration potential and a high runoff potential. Group B and C soils are designated in between these two categories.

Dual soil groups indicate infiltration properties that depend on local drainage activities. For example, Group A/D indicates poorly drained soils that could be well drained in the vicinity of roadside ditches or swales, which tend to draw down the groundwater levels. Open water features represent entirely impervious surfaces and are not assigned to a specific HSG. 


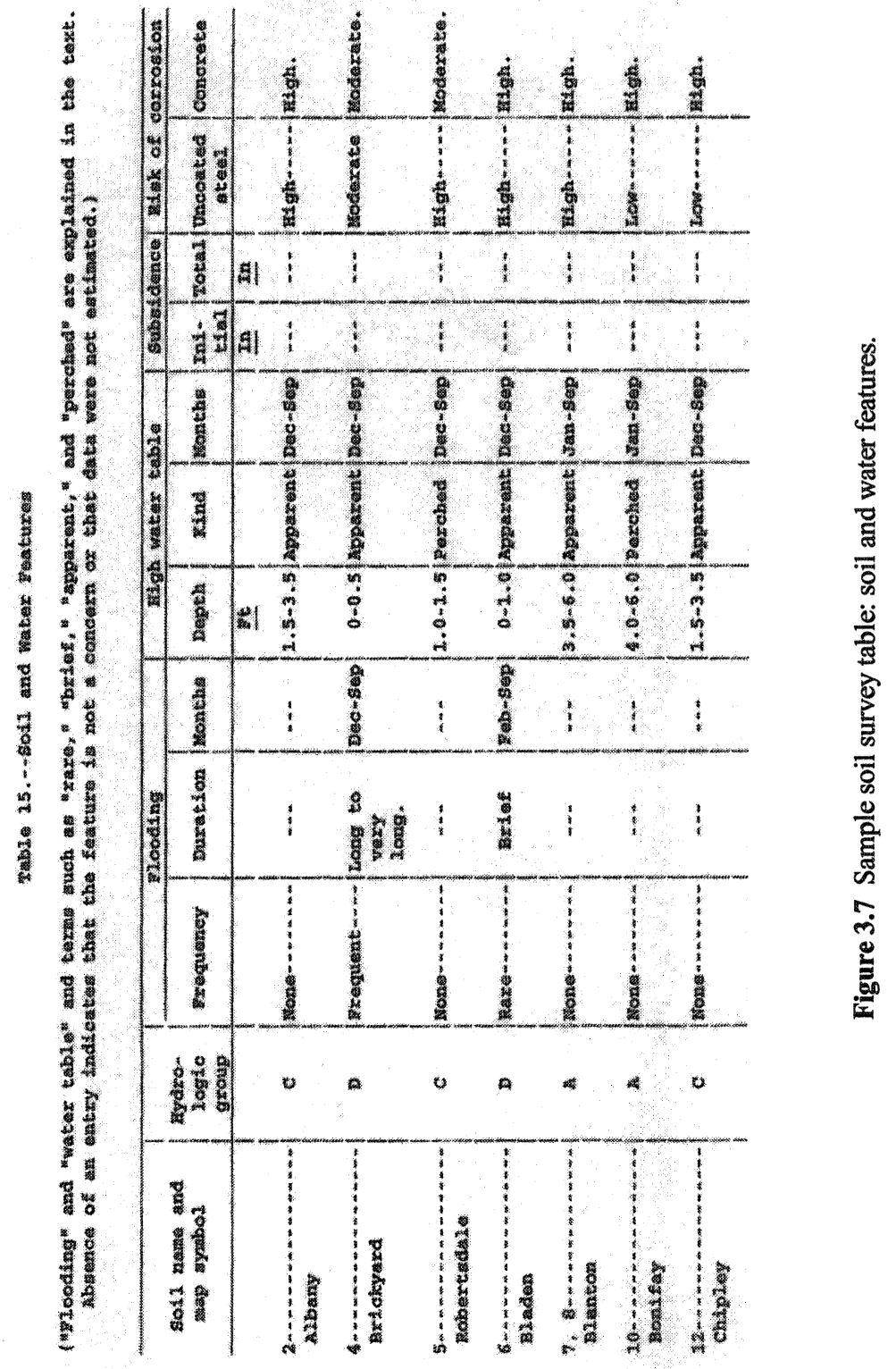




\subsection{Techniques for Estimating Soil Storage Capacity}

In this section, two methods are developed to estimate soil storage capacity based on NRCS soil survey data:

1. The first method requires the detailed soil survey data found in the Physical Analyses of Selected Soils table described earlier.

2. The second method requires the standard soil survey data found in the Physical and Chemical Properties of the Soils table described earlier.

Both methods also make use of the data found in the Soil and Water Features table described earlier.

\subsubsection{Method Using Detailed Soil Survey Data}

Table 3.1 shows the soil storage capacity calculation for a single soil map unit (i.e. Albany loamy sand) within Calhoun County, Florida, based on NRCS soil survey data. The soil map unit, bottom depth of soil sample layer, percentage of total sand, moist bulk density, and water content at $10 \mathrm{kPa}$ and $33 \mathrm{kPa}$ were taken from the NRCS tabular data sampled earlier in the section on physical analysis of selected soils (Table 16, pages 209-212 in NRCS, 2002). Entries taken from the soil survey are highlighted and the remaining values were calculated.

The water content at saturation was calculated using Equation 3.1 by assuming soil particle and water densities of $2.65 \mathrm{~g} / \mathrm{cm}^{3}$ and $1.00 \mathrm{~g} / \mathrm{cm}^{3}$, respectively (i.e. the specific gravity of the soil particle is 2.65 ). The same assumptions were used in Equation 3.2 to determine the porosity for the various water content values at $10 \mathrm{kPa}$ and $33 \mathrm{kPa}$.

The drainable porosity was then calculated as the difference between the porosity at saturation and at the field capacity. According to NRCS laboratory methods, the field capacity for sandy soils (total sand content greater than $85 \%$ ) is indicated by the water content at a tension of $10 \mathrm{kPa}$. For other soils (total sand content less than $85 \%$ ), the field capacity is indicated by the water content at a tension of $33 \mathrm{kPa}$.

The hydrologic soil group and estimate of the seasonal high water table depth shown in Table 3.1 were taken from the NRCS tabular data sampled earlier in section on soil and water features (Table 15, pages 205-208 in NRCS, 2002). For the purposes of this study, dual soil groups were treated as Group D. Of the 114 soil map units studied, a total of five were Group A/D soils and 
Table 3.1 Calculation of soil storage capacity using detailed soil survey data.

\begin{tabular}{|c|c|c|c|c|c|c|c|c|c|c|c|c|c|}
\hline Soil & Bottom & Total & Moist Bulk & \multicolumn{3}{|c|}{ Water Content } & \multicolumn{3}{|c|}{ Porosity } & Drainable & \multirow[t]{2}{*}{ HSG } & \multirow{2}{*}{$\begin{array}{c}\text { HWT } \\
\text { Depth } \\
\text { (in) }\end{array}$} & \multirow{2}{*}{$\begin{array}{c}\text { Storage } \\
\text { Cap acity } \\
\text { (in) }\end{array}$} \\
\hline $\begin{array}{l}\text { Map } \\
\text { Unit }\end{array}$ & $\begin{array}{c}\text { Depth } \\
\text { (in) }\end{array}$ & Sand & $\begin{array}{l}\text { Density } \\
\left(\mathrm{g} / \mathrm{cm}^{3}\right)\end{array}$ & $\begin{array}{c}\text { At } \\
\text { Sat'n }\end{array}$ & $\begin{array}{c}\text { At } \\
10 \mathrm{kPa}\end{array}$ & $\begin{array}{c}\text { At } \\
33 \mathrm{kPa}\end{array}$ & $\begin{array}{c}\text { At } \\
\text { Sat'n }\end{array}$ & $\begin{array}{c}\text { At } \\
10 \mathrm{kPa}\end{array}$ & $\begin{array}{c}\text { At } \\
33 \mathrm{kPa}\end{array}$ & $\begin{array}{c}\text { Porosity } \\
\text { (in/in) }\end{array}$ & & & \\
\hline \multirow{6}{*}{$\begin{array}{c}2 \\
\text { Albany } \\
\text { loamy } \\
\text { sand }\end{array}$} & 8 & $86.5 \%$ & 1.61 & $64.3 \%$ & $17.7 \%$ & $7.2 \%$ & $63.0 \%$ & $48.4 \%$ & $43.3 \%$ & $14.6 \%$ & $\bar{C}$ & 30 & \multirow[t]{6}{*}{5.49} \\
\hline & 14 & $85.6 \%$ & 1.63 & $61.1 \%$ & $8.8 \%$ & $5.1 \%$ & $61.8 \%$ & $43.5 \%$ & $41.5 \%$ & $18.4 \%$ & & & \\
\hline & 29 & $86.5 \%$ & 1.59 & $67.8 \%$ & $7.4 \%$ & $4.6 \%$ & $64.2 \%$ & $44.1 \%$ & $42.6 \%$ & $20.1 \%$ & & & \\
\hline & 46 & $85.4 \%$ & 1.58 & $69.6 \%$ & $8.0 \%$ & $5.2 \%$ & $64.8 \%$ & $44.8 \%$ & $43.3 \%$ & $20.1 \%$ & & & \\
\hline & 61 & $80.4 \%$ & 1.83 & $37.3 \%$ & $9.6 \%$ & $7.0 \%$ & $49.7 \%$ & $37.0 \%$ & $35.5 \%$ & $14.2 \%$ & & & \\
\hline & 80 & $64.2 \%$ & 1.64 & $59.6 \%$ & $18.4 \%$ & $15.6 \%$ & $61.2 \%$ & $47.7 \%$ & $46.5 \%$ & $14.7 \%$ & & & \\
\hline
\end{tabular}

Table 3.2 Average water content at field capacity by hydrologic soil group.

\begin{tabular}{|c|c|c|c|c|c|c|c|c|c|c|c|c|c|c|c|c|}
\hline \multirow[t]{2}{*}{ HSG } & \multicolumn{2}{|c|}{ Bay Co. } & \multicolumn{2}{|c|}{ Calhoun } & \multicolumn{2}{|c|}{ Citrus Co. } & \multicolumn{2}{|c|}{ Hernando Co. } & \multicolumn{2}{|c|}{ Leon Co. } & \multicolumn{2}{|c|}{ Pasco Co. } & \multicolumn{2}{|c|}{ Polk Co. } & \multicolumn{2}{|c|}{ All Counties } \\
\hline & No. & Avg. & No. & Avg. & No. & Avg. & No. $\mid$ & Avg. & No. & Avg. & No. & Avg. & No. & Avg. & No. & Avg. \\
\hline $\mathrm{A}$ & 29 & $5.0 \%$ & 25 & $7.1 \%$ & 34 & $7.6 \%$ & 40 & $7.4 \%$ & 60 & $8.2 \%$ & 41 & $7.8 \%$ & 29 & $5.4 \%$ & 258 & $7.1 \%$ \\
\hline $\mathrm{B}$ & 14 & $9.6 \%$ & 17 & $10.9 \%$ & 0 & & 0 & & 28 & $15.2 \%$ & 0 & & 0 & & 59 & $12.6 \%$ \\
\hline $\mathrm{C}$ & 12 & $6.9 \%$ & 38 & $12.9 \%$ & 32 & $16.1 \%$ & 6 & $15.0 \%$ & 25 & $12.4 \%$ & 53 & $13.1 \%$ & 16 & $7.4 \%$ & 182 & $12.7 \%$ \\
\hline D & 15 & $9.5 \%$ & 11 & $15.3 \%$ & 17 & $18.6 \%$ & 29 & $14.5 \%$ & 58 & $14.9 \%$ & 49 & $15.6 \%$ & 39 & $12.3 \%$ & 218 & $14.5 \%$ \\
\hline
\end{tabular}

Table 3.3 Calculation of soil storage capacity using standard soil survey data.

\begin{tabular}{|c|c|c|c|c|c|c|c|c|c|c|c|c|}
\hline \multirow{3}{*}{$\begin{array}{l}\text { Soil } \\
\text { Map } \\
\text { Unit }\end{array}$} & \multirow{3}{*}{$\begin{array}{l}\text { Bottom } \\
\text { Depth } \\
\text { (in) }\end{array}$} & \multirow{2}{*}{\multicolumn{3}{|c|}{$\begin{array}{c}\text { Moist Bulk Density } \\
\left(\mathrm{g} / \mathrm{cm}^{3}\right)\end{array}$}} & \multicolumn{2}{|c|}{ Water Content } & \multicolumn{2}{|c|}{ Porosity } & \multirow{3}{*}{$\begin{array}{c}\text { Drainable } \\
\text { Porosity } \\
\text { (in/in) }\end{array}$} & \multirow[t]{3}{*}{ HSG } & \multirow{3}{*}{\begin{tabular}{|c|} 
HWT \\
Depth \\
(in) \\
\end{tabular}} & \multirow{3}{*}{$\begin{array}{c}\text { Storage } \\
\text { Capacity } \\
\text { (in) }\end{array}$} \\
\hline & & & & & At & At Field & At & At Field & & & & \\
\hline & & Min & Max & Average & Sat'n & acity & Sat'n & Capacity & & & & \\
\hline 2 & 61 & 1.40 & 1.65 & 1.53 & $80.9 \%$ & $12.9 \%$ & $68.2 \%$ & $49.0 \%$ & $19.1 \%$ & Cा & $30 \mid$ & 5.74 \\
\hline llany & 80 & 1.55 & 1.85 & 1.70 & $51.2 \%$ & $12.9 \%$ & $57.6 \%$ & $43.2 \%$ & $14.4 \%$ & & & \\
\hline
\end{tabular}


19 were Group B/D soils. The HWT depth listed in Table 3.1 is the average value of the range reported in the soil survey. For this study, a maximum value of $72 \mathrm{in}(508 \mathrm{~mm})$ was used where the HWT depth was reported in the soil survey as greater than $6 \mathrm{ft}(1.8 \mathrm{~m})$, and a minimum value of 6 in $(153 \mathrm{~mm})$ was used where the HWT depth was reported as zero or above the ground surface.

The final column in Table 3.1 shows the soil storage capacity for the map unit. As mentioned earlier, the soil storage capacity is simply the drainable porosity times the depth of the unsaturated soil layer (i.e. between the ground surface and the high water table). For multi-layer soils, the soil storage capacity in each soil layer that lies above the high water table is summed to give the total soil storage capacity for the map unit. The unsaturated zone in this example is 30 in deep, which includes all of the first three layers plus 1 inch within the fourth layer. The soil storage capacity for Albany loamy sand is:

$S=(8$ in $\times 14.6 \%)+(6$ in $\times 18.4 \%)+(15$ in $\times 20.1 \%)+(1$ in $\times 20.1 \%)$ $=5.49 \mathrm{in}$.

Soil storage capacities were calculated using this methodology for 114 soil map units in seven Florida counties, including:

- 13 soil map units in Bay County (northwest Florida)

- 17 soil map units in Calhoun County (northwest Florida)

- 15 soil map units in Citrus County (west central Florida)

- 11 soil map units in Hernando County (west central Florida)

- 25 soil map units in Leon County (northwest Florida)

- 19 soil map units in Pasco County (west central Florida)

- 14 soil map units in Polk County (central Florida)

As mentioned earlier, the detailed soils data used to compute soil storage capacity using the methodology described above is not available in all county soil surveys. Most county soil surveys include the standard data that forms the basis for the second method described below. In order to use the second method, an assumption about the water content at field capacity must be made, since this information is not included in the standard soil survey table.

Table 3.2 shows the average measured water content at field capacity (for the $10 \mathrm{kPa}$ and $33 \mathrm{kPa}$ measurements combined), grouped by hydrologic soil group. This average was determined for each layer of all soil map units included in the detailed survey data calculations, representing a total of 717 layers. Results varied somewhat by county. Overall, the water content of Group A soils ranged from 5 to $8 \%$ and Group B, C, and D soils ranged from 7 to $19 \%$. For all counties combined, Group A soils had an average water content of $7 \%$, while the remaining groups averaged between 13 and $15 \%$ as shown in the final column of Table 3.2 . 
The standard soil survey data tables include moist bulk density ranges by layer for each soil map unit. Unfortunately, no correlation was found between the average water content at field capacity and the moist bulk density. In addition, no correlation was found between the average water content at field capacity and the bottom depth of the layer (as percentage of the HWT depth).

\subsubsection{Method Using Standard Soil Survey Data}

The second method for estimating soil storage capacity uses tabular soil data that are common for most county soil surveys in the U.S.

Table 3.3 shows the soil storage capacity calculation for a single soil map unit (i.e. Albany loamy sand) within Calhoun County, Florida, based on NRCS soil survey data. The soil map unit, bottom depth of soil sample layer, and range of moist bulk densities were taken from the NRCS tabular data sampled earlier in th section on physical and chemical properties of the soils (Table 14, pages 199-204 in NRCS, 2002). Entries taken from the soil survey are highlighted and the remaining values were calculated.

For this study, the average moist bulk density was used in the calculations. The water content at saturation was calculated using Equation 3.1 with the soil particle and water density assumptions that were discussed in the first method. As explained earlier, an estimate of the water content at the field capacity was required in order to calculate the porosity values, since water content values at specific tensions are not given in the standard NRCS tabular data. In this case, a value of $12.9 \%$ was chosen, which represents the average water content for all Group C soils in Calhoun County using the detailed soil survey data in the first method.

The porosity at saturation and at the estimated water content was calculated using Equation 3.2, and the drainable porosity was calculated as the difference between these two values.

The hydrologic soil group and estimate of the seasonal high water table depth shown in Table 3.3 were taken from the NRCS tabular data sampled earlier in the section on soil and water features (Table 15, pages 205-208 in NRCS, 2002) as described earlier.

The final column in Table 3.3 shows the soil storage capacity for the map unit, calculated as the sum of the product of drainable porosity times the layer depth for all layers above the HWT. Of the two defined layers in the soil sample, the unsaturated soil zone is contained within the first layer only. The soil storage capacity for Albany loamy sand is:

$$
S=(30 \text { in } \times 19.1 \%)=5.74 \text { in }
$$


which is approximately $5 \%$ greater than the value calculated using the first method (5.49 in or $140 \mathrm{~mm}$ ).

Soil storage capacities were calculated using this methodology for 103 soil map units in six Florida counties. Hernando County data could not be used since moist bulk density estimates were not included in the standard soil properties (Table 15, pages 132-135 in SCS, 1977).

\subsection{Results and Discussion}

In this section, the results between the two methods are compared. In addition, the discussion includes a number of practical considerations when applying the parameter estimation methods for surface water hydrologic analyses.

\subsubsection{Comparison Between Parameter Estimation Methods}

Figure 3.8 shows the comparison between soil storage capacities obtained using the standard and detailed soil survey data methodologies described in this chapter. The figure compares the soil storage capacity for 103 soil map units. The second method (using the standard soil survey data) used an estimate of the water content at field capacity that was determined from the first method (using the detailed soil survey data) for the corresponding county. On average, results using the standard soil survey data underpredicted those using the detailed soil survey data by $2.5 \%$, with individual soil map unit differences ranging from -36.5 to $31.5 \%$.

When results were grouped according to county, the computation using the standard survey data came within $4 \%$ for all counties compared to results using the detailed survey data, with the exception of Citrus County, which was off by $9.1 \%$. Results were not significantly different whether the water content was estimated using the appropriate county average or the average for all counties as shown in Table 3.2.

\subsubsection{Estimating Water Content at Field Capacity}

The second method will generally be the most widely used, since the required data are available in most county soil surveys. As mentioned earlier, the methodology requires an estimate of the water content at field capacity. In section 3.3.1, statistics were developed that related water content to the hydrologic soil group. 


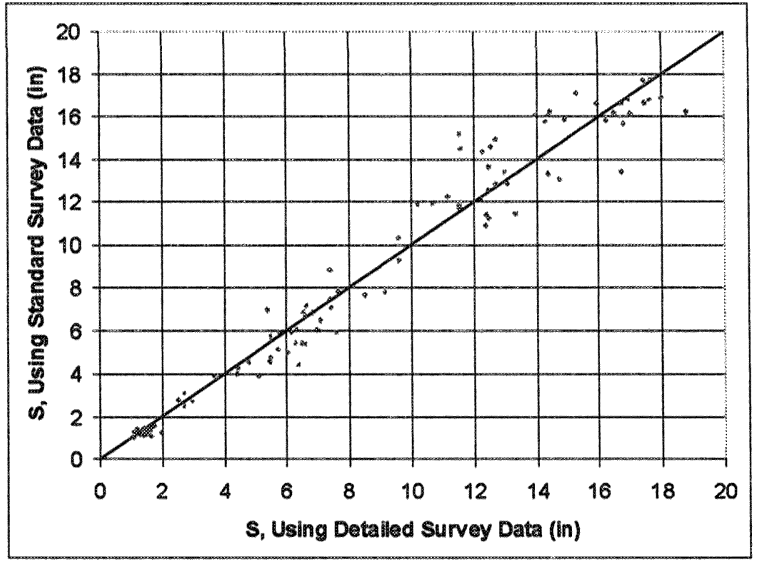

Figure 3.8 Soil storage capacity comparison using standard and detailed soil survey data.

Results in section 3.4.1 suggest that using the statistical average for all counties is appropriate for estimating the water content at field capacity. Table 3.4 shows the values recommended for watersheds in northwest and west central Florida. These values are restated from the results presented in Table 3.2.

Table 3.4 Recommended water content values (at field capacity).

\begin{tabular}{ll}
\hline Hydrologic Soil group & Water Content \\
\hline A & $7.1 \%$ \\
B & $12.6 \%$ \\
C & $12.7 \%$ \\
D & $14.5 \%$ \\
\hline
\end{tabular}

\subsubsection{Estimating Soil Storage Capacity for Various Antecedent Moisture Conditions}

When modeling discrete events (e.g. historical storm events for calibration, or design storm events for analysis), antecedent moisture conditions are often assumed or specified. Soil storage capacity is directly related to these assumptions. Since the equations describe soil properties under field capacity conditions, the methods presented in this chapter apply to dry antecedent moisture conditions. 
The NRCS has developed methods for computing runoff during rainfall events based on measurements in many small experimental watersheds (SCS, 1972). With these methods, runoff is related to the rainfall according to a runoff curve number, which is selected based on land use type and HSG. The relationship between curve number and the soil storage capacity is:

$$
\mathrm{S}=\frac{1000}{C N}-10
$$

where:

$$
\begin{aligned}
S & =\text { soil storage capacity (in), and } \\
C N & =\text { runoff curve number (dimensionless). }
\end{aligned}
$$

In order to apply NRCS methods to conditions when the unsaturated zone initially contains more water than at the measured field capacity (e.g. due to recent rainfall and/or high groundwater conditions), various antecedent moisture conditions (AMCs) have been defined, including:

- AMCdry, when total rainfall over the previous 5 days is less than 1.4 in

- AMCnorm, when total rainfall over the previous 5 days is between 1.4 and 2.1 in

- AMCwet, when total rainfall over the previous 5 days is greater than 2.1 in

The rainfall conditions stated above should only be considered approximate guidelines for identifying the AMC prior to a rainfall event. It is more appropriate to consider the soil water status in terms of the field conditions shown in Figure 3.2. As stated earlier, the estimation methods in this chapter apply to field capacity conditions. If drier conditions exist (e.g. near wilting point), estimates of soil storage capacity should be increased. If wetter conditions exist (e.g. due to antecedent rainfall), estimates of soil storage capacity should be decreased.

Equivalent curve numbers can be determined for either dry or wet conditions based on the following NRCS empirical equations:

$$
C N_{d r y}=\frac{4.2 \times C N}{10-0.058 \times C N}
$$

and

$$
C N_{\text {wet }}=\frac{23 \times C N}{10+0.13 \times C N}
$$


where:

$$
\begin{aligned}
C N= & \text { runoff curve number under } \mathrm{AMC}_{\text {norm }} \text { conditions, } \\
C N_{d r y}= & \text { the equivalent runoff curve number under } \mathrm{AMC}_{\mathrm{dry}} \\
& \text { conditions, and } \\
C N_{\text {wet }}= & \text { the equivalent runoff curve number under } \mathrm{AMC}_{\text {wet }} \\
& \text { conditions. }
\end{aligned}
$$

By combining Equation 3.5 with Equations 3.6 and 3.7, the soil storage capacities developed using the methodologies described in this chapter (i.e., AMCdry conditions) can be converted to AMCnorm and AMCwet conditions. When calibrating surface water models to discrete storm events, the modeler must select the appropriate AMC to estimate the soil storage capacity. For analysis and design applications, it is common practice to assume AMCnorm conditions, and the estimated soil storage capacity should be revised accordingly. When applying continuous simulation to surface water models, the estimated soils storage capacity using AMCdry conditions would be appropriate, unless drought conditions are included in the simulation period. In that case, revised estimates of the water content (at less than the field capacity) should be considered when estimating the soil storage capacity.

\subsubsection{Comparison to Other Methods}

The premise of this chapter is that storage capacity is more appropriately based on measured soil and water properties rather than simple indicators of soil (e.g. HSG) or land use (e.g. CN) classifications that are commonly used. This section compares results to other popular methods that use such simplified indicators. While a direct comparison between results has limited value, it does help to put all estimation methods into perspective.

Table 3.5 shows the average soil storage capacity calculated using the detailed soil survey data methodology described above, grouped by HSG. Results also varied slightly between counties. Overall, the soil storage capacity for Group A soils ranged from 14 to 15 in (356 to $381 \mathrm{~mm}$ ). Group B soils ranged from 9 to 10 in ( 229 to $254 \mathrm{~mm}$ ), however the sample size was very small (i.e. 9 out of 114 soil map units). Group C and D soils ranged from 5 to 7 in (127 to $178 \mathrm{~mm}$ ) and 1 to 3 in $(25$ to $76 \mathrm{~mm})$, respectively. For all counties combined, the average soil storage capacity for Group A, B, C, and D soils was $14.6,9.7,6.1$, and 2.0 in $(371,246,155$, and $508 \mathrm{~mm})$, respectively, as shown in the last column of Table 3.5. 
Table 3.5 Average soil storage capacity (in) by hydrologic soil group.

\begin{tabular}{|l|r|r|r|r|r|r|r|r|r|r|r|r|r|r|r|r|}
\hline HSG & \multicolumn{2}{|c|}{ Bay Co. } & \multicolumn{2}{c|}{ Calhoun Co. } & \multicolumn{2}{c|}{ Citrus Co. } & \multicolumn{2}{|c|}{ Hernando Co. } & \multicolumn{2}{c|}{ Leon Co. } & \multicolumn{2}{c|}{ Pasco Co. } & \multicolumn{2}{c|}{ Polk Co. } & \multicolumn{2}{c}{ All Counties } \\
& No. & Avg. & No. & Avg. & No. & Avg. & No. & Avg. & No. & Avg. & No. & Avg. & No. & Avg. & No. & Avg. \\
\hline A & 5 & 14.5 & 5 & 15.1 & 7 & 15.1 & 6 & 14.8 & 9 & 13.6 & 6 & 14.5 & 6 & 14.9 & 44 & 14.6 \\
\hline B & 2 & 9.6 & 3 & 9.1 & 0 & & 0 & & 4 & 10.2 & 0 & & 0 & & 9 & 9.7 \\
\hline C & 2 & 7.0 & 7 & 5.2 & 5 & 6.7 & 1 & 5.6 & 4 & 5.3 & 7 & 6.3 & 3 & 7.2 & 29 & 6.1 \\
\hline D & 4 & 2.9 & 2 & 2.1 & 3 & 3.3 & 4 & 1.3 & 8 & 2.1 & 6 & 1.6 & 5 & 1.4 & 32 & 2.0 \\
\hline
\end{tabular}

Table 3.6 Soil storage capacity comparisons.

\begin{tabular}{|l|r|r|r|r|r|r|r|r|} 
& $\mathrm{AMC}_{\text {dry }}$ & $\mathrm{AMC}_{\text {norm }}$ & $\mathrm{AMC}_{\text {wet }}$ & $\mathrm{AMC}_{\text {dry }}$ & $\mathrm{AMC}_{\text {norm }}$ & $\mathrm{AMC}_{\text {wet }}$ & Calc'd $^{3}$ & Typical $^{4}$ \\
\hline $\mathrm{A}$ & 14.6 & 6.2 & 2.7 & $4.3-12.0$ & $3.4-5.4$ & $1.8-2.1$ & 62 & $39-68$ \\
\hline $\mathrm{B}$ & 9.7 & 4.1 & 1.8 & $3.4-9.0$ & $2.8-4.0$ & $1.3-1.5$ & 71 & $61-79$ \\
\hline $\mathrm{C}$ & 6.1 & 2.6 & 1.1 & $2.3-7.0$ & $1.8-3.0$ & $0.8-1.0$ & 80 & $74-86$ \\
\hline $\mathrm{D}$ & 2.0 & 0.8 & 0.4 & $1.3-3.0$ & $1.0-1.3$ & $0.5-0.7$ & 92 & $80-89$ \\
\hline
\end{tabular}

Notes:

1. Based on $A M C_{\text {dry }}$ values determined in this study (average for all counties in Table 5).

2. From Table 4-3, Standard Infiltration Parameters for Pervious Areas (CDM, 1994).

3. Calculated using equation (5) with $\mathrm{AMC}_{\text {norm }}$ value described in note 1 .

4. From Table 5.5.2, Runoff Curve Numbers for Selected Land Uses (Chow et al., 1988). 
Table 3.6 shows the comparison of soil storage capacities according to HSG. The average soil storage capacity values for all counties shown in Table 3.5 were applied to the various AMC conditions in the first three columns, as described in section 3.4.3 above. These values are compared to a range of typical values obtained in watershed master planning studies throughout Florida (CDM, 1994). Values calculated from the detailed survey data in this study generally lie within the range of typical values shown.

The runoff curve number for AMCnorm conditions was determined from Equation 3.5 and compared to typical NRCS values. A range of curve numbers for Pasture or Range Land land uses is given in the final column of Table 3.6. The minimum value identifies a good condition and the maximum value identifies a poor condition. The values calculated from the detailed survey data in this study are generally within this range.

\subsection{Conclusions}

The purpose of this chapter was to present and evaluate methods for estimating the capacity of soils to store infiltrated runoff based on available soil survey data and modified unsaturated infiltration assumptions. The methods presented in this chapter make use of published soil survey data, unlike existing methods that are based on very general soil or land use characteristics. Soil storage capacity values were computed for 114 soil map units in seven Florida counties and results compared favorably with typical published values.

The preferred method involves the use of detailed NRCS county soil survey data. However, the necessary data are not always available for every county. An alternative method was developed that uses standard NRCS soil survey data, which are available for most counties. To use this method, an estimate of the water content at field capacity is required. For this study, the water content was estimated based on the average value for each hydrologic soil group (determined using the detailed soil survey data).

Finally, a number of practical considerations should be taken into account when applying the methods presented in this chapter:

- The methods developed in this study apply to dry antecedent moisture conditions. When using discrete design or historical storm events, the soil storage capacity must be adjusted to reflect the appropriate antecedent moisture condition (i.e. dry, normal, or wet). Normal antecedent conditions are commonly used for design applications. 
- The NRCS soil survey data are based on measurements of native, undisturbed soil samples. These data might not apply in urbanized areas where, for example, new soil has been imported for landscaping activities or earthwork operations have resulted in significantly compacted soil.

- For this study, the water table depth was taken as the average of the range reported in the NRCS soil survey. If available, it is better to use local well data or soil testing for seasonal high water determination, since localized water table depths may vary widely from the general soil survey range.

\subsection{References}

Bedient, P. B. and Huber, W. C., 1992. Hydrology and Floodplain Analysis (Second Edition). Addison-Wesley Publishing Company.

Camp Dresser \& McKee Inc., 1994. CDM-RUNOFF User's Manual and Documentation (Draft).

Chow, V. T., Maidment, D. R., and Mays, L. W., 1988. Applied Hydrology. McGrawHill, Inc.

Haan, C. T., Johnson, H. P., and Brakensiek, D. L. (Editors), 1982. Hydrologic Modeling of Small Watersheds. American Society of Agricultural Engineers.

Horton, R.E., 1939. Analysis of Runoff Plot Experiments with Varying Infiltration Capacity. Transactions of the American Geophysical Union, Volume 20, pages 683-694.

Huber, W. C. and Dickinson, R. E., 1988. SWMM Version 4 User's Manual. US Environmental Protection Agency.

Johanson, R.C., Imhoff, J.C., Kittle Jr., J.L. and Donigian Jr., A.S., 1984. HSPF User's Manual for Release 8.0. US Environmental Protection Agency.

Natural Resources Conservation Service, 2002. Soil Survey of Calhoun County, Florida. US Department of Agriculture.

Pitt, R.E. and J. Lantrip. 2000. "Infiltration Through Disturbed Urban Soils." Journal of Water Management Modeling R206-01. doi: 10.14796/JWMM.R206-01.

Soil Conservation Service, 1972. National Engineering Handbook, Section 4: Hydrology. US Department of Agriculture.

Soil Conservation Service, 1977. Soil Survey of Hernando County, Florida. US Department of Agriculture.

Soil Conservation Service, 1981. Soil Survey of Leon County, Florida. US Department of Agriculture.

Soil Conservation Service, 1982. Soil Survey of Pasco County, Florida. US 
Department of Agriculture.

Soil Conservation Service, 1984. Soil Survey of Bay County, Florida. US Department of Agriculture.

Soil Conservation Service, 1988. Soil Survey of Citrus County, Florida. US Department of Agriculture.

Soil Conservation Service, 1990. Soil Survey of Polk County, Florida. US Department of Agriculture. 